\title{
Analisis Perbandingan Kondisi Existing dengan Metode Economic Order Quantity (EOQ) dalam menentukan Jumlah Persedian Bahan Baku WCP2 dan 7HF
}

\author{
Larisang $^{* 1}$, Zeri Yusdianata ${ }^{2}$, Bahari Syaputra ${ }^{3}$ \\ 1,2,3Sekolah Tinggi Teknik,Jalan Teuku Umar -Lubuk Baja,(0778) 25391 \\ Program Studi Teknik Industri, STT Ibnu Sina, Batam \\ e-mail: *1 larisang01@yahoo.co.id, ${ }^{2}$ zeri@ stt-ibnusina.ac.id, \\ baharisyaputra@yahoo.co.id
}

\begin{abstract}
ABSTRAK
Berdasarkan data yang diperoleh dari perusahaan pada tahun 2017 PT. Sucofindo Batam melakukan kebijakan pembelian berdasarkan order dari customer. Dalam hal ini dengan menggunakan Metode Economic Order Quality (EOQ), maka perusahan lebih hemat dari total biaya (Total Cost) persediaan yang dilakukan oleh perusahaan. Dengan jumlah penghematan biaya sebesar Rp. Rp. 24.517.276 atau sekitar 8,6\% untuk White Contrast Paint (WCP-2) dalam setahun. Sedangkan untuk Black Ink (7HF) juga terjadi penghematan pemesanan persedian sebesar Rp. 23.212 .522 atau sekitar $15 \%$ dalam setahun. Dengan ini perusahan dapat mengurangi tingkat resiko keterlambatan dalam melakukan inspeksi, untuk Frekuensi pemesanan dengan menggunakan metode EOQ bahan baku WCP2 dan 7HF akan lebih efesien dan kondusif. Untuk Safety Stock perusahaan bisa mengetahui jumlah persedian bahan baku WCP-2 dan 7HF yang optimal sebagai bahan baku pengaman ketersedian. Untuk ROP perusahan tidak mengalami kehabisan dan kekurangan bahan baku dan mengindari terjadinya keterlambatan melakukan kegiatan Magnetic Particle Testing (MPI).
\end{abstract}

Kata kunci-Kata kunci: Economic Order Quantity, Total Cost, Safety Stock. ROP

\section{ABSTRACTS}

Based on data obtained from the company in 2017 PT. Sucofindo Batam makes purchasing policy based on order from customer. In this case by using Method Economic Order Quality (EOQ), then the company will be more efficient than total cost (Total Cost) inventory made by the company. With a total cost savings of Rp. Rp. 24,517,276 or about $8.6 \%$ for White Contrast Paint (WCP-2) in a year. As for the Black Ink (7HF) also occurs savings booking of supplies for Rp. 23.212 .522 or about 15\% in a year. With this company can reduce the level of risk of delay in conducting inspections, for Frequency booking using EOQ method of raw materials WCP2 and 7HF will be more efficient and conducive. For Safety Stock company can know the amount of raw material supply WCP-2 and 7HF optimal as raw material of safety of availability. For ROP the company does not run out and lack of raw materials and avoid the occurrence of delay doing Magnetic Particle Testing (MPI).

Keywords-Keywords: Economic Order Quantity, Total Cost, Safety Stock. ROP.

\section{PENDAHULUAN}

Setiap perusahaan harus dapat menentukan lebih dahulu besarnya persediaan bahan baku yang dibutuhkan untuk menghasilkan sejumlah barang jadi yang direncanakan dalam suatu 
periode tertentu. Hal ini penting untuk menjaga agar tidak terjadi kekurangan bahan baku yang dapat menghentikan proses produksi dan akan menimbulkan kerugian bagi perusahaan karena tidak memenuhi permintaan konsumen terhadap barang jadi. Suatu perusahaan mempunyai tujuan untuk mendapatkan keuntungan yang optimal. Dengan perusahaan jasa maupun perusahaan manufaktur pasti tujuan utamanya adalah memperoleh keuntungan yang optimal.

Keuntungan yang optimal dapat diperoleh jika perusahaan mampu menjalankan manajemen perusahaan dengan baik. Manajemen perusahaan mempunyai peranan yang sangat penting, yaitu sebagai alat kontrol untuk menjalankan kegiatan perusahaan agar tetap bergerak secara efisien dan mampu menghasilkan keuntungan yang optimal. Persediaan yang optimal akan membantu mengefisiensikan pengeluaran biaya, seperti biaya pemesanan maupun biaya penyimpanan bahan baku.

Menurut Sudana (2011:227) EOQ adalah jumlah persediaan yang harus dipesan dengan biaya yang minimal. Dalam model EOQ biaya persediaan yang dipertimbangkan adalah biaya penyimpanan persediaan dan biaya pemesanan persediaan. Dalam Economic Order Quantity (EOQ) merupakan metode manajemen persediaan yang menentukan jumlah pemesanan dan pembelian yang harus dilakukan dan berapa banyak jumlah yang harus dipesan agar biaya total penjumlahan antara biaya pemesanan dan biaya penyimpanan menjadi minimum. Dengan demikian untuk menghitung jumlah pesanan yang ekonomis perlu dilihat pertambahan biaya pemesanan dan biaya penyimpanan serta besarnya persediaan rata-rata. Terkait dengan hal ini, maka dengan ini penulis mengadakan penelitian pada PT. Sucofindo Batam yaitu sebuah perusahaan yang bergerak dibidang sektor bisnis dan jasa inspeksi

Dalam pelaksanaan inspeksi PT. Sucofindo Batam tersebut menggunakan beberapa bahan inspeksi seperti White Contrast Pain (WCP) untuk bahan baku sendiri perusahaan melakukan pemesanan sebanyak 12 kali dalam periode satu tahun. Perusahan mengalami kehabisan bahan persedian Magnaflux Consumable WCP2 terjadi 3 kali dalam 1 tahun ini ,sehingga mengakibatkan keterlambatan jadwal pemeriksaan karena Magnaflux Consumable WCP2 dan 7HF ini dibutuhkan dalam pengujian MPI (Magnetic Particle Testing). Bahan baku WCP2 dan 7HF ini adalah sebagai bahan baku digunakan untuk mengetahui cacat permukaan pada material atau welding yang diperiksa dalam pendukung kegiatan sertifikasi. Dengan terjadinnya kehabisan bahan baku ini dapat mempengaruhi kepuasan pelanggan, waktu yang hilang, terhentinya pekerjaan dan hilangnya order.

Dari laporan persediaan diatas dapat dilihat PT. Sucofindo Batam melakukan kebijakan pembelian berdasarkan tergantung dalam permintaan order dari coustemer. Dalam hal ini perusahan kurangnya menerapkan dalam persedian bahan baku, hanya berdasarkan kartu permintaan barang,metode yang digunakan oleh perusahan dalam penyediaaan bahan baku Magnaflux Consumble ini dengan berdasarkan order,dibantu alat computer serta dengan mengunakan kartu permintaan dan perhitungan perusahan.

\section{METODE PENELITIAN}

\subsection{Waktu dan tempat penelitian}

Waktu dan tempat penelitian ini dilaksanakan pada tanggal 28 November 2017 sampai dengan 28 Februari 2018 dan penelitain ini dilakukan di lokasi yang digunakan sebagai obyek penelitian ini adalah PT Sucofindo Batam dengan alamat Batam Graha Sucofindo Jl. Raden Patah No. 61, Baloi Batam. Penulis memilih melakukan penelitian PT Sucofindo Cabang Batam masih terdapat beberapa masalah yang berhubungan dengan persediaan bahan baku White Contrast Point (WCP-2) dan Black Ink (7 HF) diperusahan.

\subsection{Jenis Data}

Jenis dan Sumber data penelitian merupakan sumber data yang diperlukan untuk penelitian dengan melihat metode apa yang digunakan untuk melakukan pengukuran. Dengan metode penelitian maka seorang peneliti dapat memiliki gambaran mengenai langkah-langkah 
dalam melakukan penelitian dan dapat memecahkan masalah dalam penelitian tersebut. Dalam melakukan sebuah penelitian, hal pertama yang harus dilakukan adalah menetapkan terlebih dahulu metode apa yang akan digunakan. Menurut Sugiyono (2012:2), "secara umum metode penelitian diartikan sebagai cara ilmiah untuk mendapatkan data untuk tujuan dan kegunaan tertentu. Data yang diperoleh dari penelitian tersebut merupakan data yang dapat diamati atau empiris. Pengumpulan data didapat tergantung dari sumber datanya, yaitu sumber data primer dan sumber data sekunder. Sumber data yang diperoleh dalam penelitian ini adalah sebagai berikut

Dalam pengumpulan data dikumpulkan bagi penulisan penelitian ini ,maka jenis data yang dikumpulkan dikelompokan kedalam dua jenis, yaitu:

1. Data Primer

Data Primer diperoleh melalui tanya jawab dengan pemilik perusahaan (wawancara) dan observasi langsung ke dalam perusahaan. Sumber data yang digunakan dalam penelitian ini adalah data yang berkaitan dengan persediaan bahan baku/ chemiclas, data diambil pada priode tahun 2016 sampai 2017 mulai bulan januari- Desember dengan kretiria/ tolok ukur berupa :

a. Persedian bahan baku WPC2 dan 7HF

b. Pemakaian bahan baku WPC2 dan 7HF

c. Biaya harga satuan bahan baku WCP2 dan 7HF

d. Biaya Permintaaan Bahan Baku Pertahun

e. Biaya Penyimpanan bahan baku

f. Lead Time bahan baku

2. Data sekunder

Data sekunder adalah adalah data yang diperoleh melalui beberapa sumber informasi lain yang telah dikumpulkan dari sumber yang telah ada seperti dokumen-dokumen, arsip-arsip, serta buku-buku referensi yang berkaitan dengan penelitian Menurut Uma Sekaran (2011). Untuk membantu dalam penelitian analisa persedian bahan baku. Data sekunder yang dibutuhkan adalah data - data yang diperlukan yaitu:

a. Data Stock bahan baku WCP2 dan 7HF

b. Data Purchase Order bahan baku

Berdasarkan bentuk dan sifatnya, data penelitian dapat dibedakan dalam dua jenis yaitu data kualitatif (yang berbentuk kata-kata/kalimat) dan data kuantitatif (yang berbentuk angka). Data kuantitatif dapat dikelompokkan berdasarkan cara mendapatkannya yaitu data diskrit dan data kontinum. Berdasarkan sifatnya, data kuantitatif terdiri atas data nominal, data ordinal, data interval dan data rasio.

a. Data kualitatif,

Data yang disajikan dalam bentuk kata verbal bukan dalam bentuk angka. (Noeng Muhadjir) Metodologi Penelitian Kualitatif, yang termasuk data kualitatif dalam penelitian ini yaitu gambaran umum obyek penelitian, meliputi: Sejarah singkat berdirinya perusahan, , Visi dan Misi, struktur organisasi, dan jenis usaha perusahan .

b. Data kuantitatif

Jenis data yang dapat diukur atau dihitung secara langsung, yang berupa informasi atau penjelasan yang dinyatakan dengan bilangan atau berbentuk angka. Sugiyono, Statistik untuk Pendidikan. (Bandung: Alfabeta, 2013).

\subsection{Populasi dan Sample}

Populasi adalah wilayah generalisasi yang terdiri dalam objek dan subjek yang memiliki kualitas atau karakteristik tertentu yang ditetapkan oleh peneliti untuk dipelajari, kemudian ditarik kesimpulan (Sugiyono 2013). Sampel adalah sebagian atau wakil dari pupulasi yang diteliti. Jadi sampel adalah contoh yang diambil dari sebagain populasi penelitian yang dapat mewakili populasi. Walaupun yang diteliti adalah sampel, tetapi hasil penelitian atau kesimpulan penelitian berlaku untuk populasi atau kesimpulan penelitian digeneralisasikan terhadap populasi. yang 
dimaksud menggeneralisasikan adalah mengangkat kesimpulan penelitian dari sampel sebagai sesuatu yang berlaku bagi populasi.

Sampel dalam penelitian ini adalah jumlah bahan Consumable Chemical dibagian Inspeksi Teknik PT Sucofindo Batam untuk pengambilan sampel bahan baku Consumable Chemical 240 can untuk WCP2 sedangkan untuk 7 HF sekitar 120 cans total keseluruhan 360 cans.

\subsection{Variabel Penelitian dan Defenisi Operasional}

Variabel penelitian pada hakikatnya merupakan konsep yang nilainya ingin diketahui oleh peneliti. Variabel merupakan sesuatu yang menjadi objek pengamatan penelitian, sering juga disebut sebagai faktor yang berperan dalam penelitian atau gejala yang akan diteliti. Menurut Kerlinger (2006: 49), variabel adalah konstruk atau sifat yang akan dipelajari yang mempunyai nilai yang bervariasi. Kerlinger juga mengatakan bahwa variabel adalah simbol/lambang yang padanya kita letakan sebarang nilai atau bilangan. Variabel dapat dikelompokkan menurut beragam cara, namun terdapat 2 jenis yaitu:

a. Variabel Bebas X (Independent Variable)

Variabel bebas adalah variable yang mempengaruhi, yang dapat menyebabkan timbulnya atau berubahnya variable terikat.variabel bebas dalam penelitian ini adalah data Order konsumen untuk permintaan pemeriksaan MPI (Magnetic Particle Testing) pada Costoumer.

b. Variabel Terikat (Dependent Variable)

Variabel terikat adalah variabel yang dipengaruhi karena adanya variable bebas. Variabel terikat dalam penelitian ini adalah kekurangan stok pengaman bahan baku White Contrasct Paint (WCP-2) dan Black Ink (7HF).

\subsection{Metode Pengumpulan Data}

Metode pengumpulan data yang digunakan adalah :

a. Observasi lapangan

Peneliti melaksanakan survey langsung ke lapangan untuk melihat proses kegiatan penyimpanan persedian WCP2 dan 7 HF di Gudang PT Sucofindo Batam.

b. Wawancara

Peneliti dapat data ini dengan cara berdiskusi dengan orang yang bagian departemen bisnis umum dan berpengalaman di PT Sucofindo Batam.

c. Tinjauan Pustaka

Peneliti mencari informasi dari pustaka yang berhubungan dengan Pengendalian Persedian dan metode perhitungan mengunakan pendekatan Metode Economic Order Quantity

\subsection{Metode Pengolahan Data}

Analisis yang digunakan dalam penelitian ini adalah analisis kuantitatif dengan mengklasifikasi, membandingkan serta menghitung data angka-angka dengan menggunakan rumus yang relevan Setelah data-data terkumpul maka langkah selanjutnya adalah proses analisis data. Untuk membantu dalam proses analisis data ini maka dibutuhkan alat/instumen. Adapun alat/instrumen pengolahan yang dibutuhkan untuk dipergunakan dalam penelitian ini adalah :

a. Economic Order Quantity (EOQ)

Mengenai pemesanan bahan dasar perlu ditentukan bagaimana cara pemesanannya, berapa jumlah yang dipesan agar pemesanan tersebut ekonomis dan kapan pemesanan itu dilakukan. Untuk menentukan jumlah pemesanan ekonomis ini, diusahakan untuk memperkecil biaya-biaya pemesanan (ordering costs) dan biaya-biaya penyimpanan (carrying costs) dengan menggunakan indicator-indikator seperti permintaan per tahun, biaya pemesanan tiap kali pesan, dan biaya penyimpanan per unit per tahun. Rumus untuk mendapatkan EOQ yaitu 


$$
\mathrm{EOQ}=\sqrt{\left(\frac{2 D S}{H}\right)}
$$

Dimana : $\mathrm{D}=$ Permintaan tahunan dalam unit untuk barang persediaan.

$\mathrm{S}=$ Biaya pemesanan untuk setiap pesanan.

$\mathrm{H}=$ Biaya penyimpanan

b. Total Biaya Persediaan

Sebagaimana telah disebutkan bahwa jumlah pembelian pada persediaan bahan baku dilakukan karena pengawasan dan pengadaan bahan dasar lebih didasarkan pada pengalaman periode-periode sebelumnya.,bukan didasarkan pada perhitungan-perhitungan secara ekonomis. Biaya persediaan juga dapat dinyatakan dengan menyertakan biaya pembelian dari bahan baku tersebut., perhitungan total biaya persediaan tahunan dapat dihitung dengan menggunakan rumus sebagai berikut :

$$
\mathrm{TC}=\mathrm{DP} \frac{D}{Q} \cdot S+\frac{Q}{2} \cdot H
$$

c. Frekuensi Pemesanan $(\mathrm{F})$

Dari EOQ tersebut $\left(Q^{*}\right)$ dapat diketahui jumlah frekuensi pemesanan selama satu tahun $(N)$ dan waktu interval antar pemesanan atau $T$ dengan cara sebagai berikut :

$$
\mathrm{F}=\frac{D}{Q *}
$$

Dimana: $F=$ Frekuensi Pemesanan Selama Satu Tahun

$$
\begin{aligned}
& D=\text { Permintaan } / \text { Demand } \\
& Q *=\mathrm{EOQ}
\end{aligned}
$$

d. Penentuan Persedian Pengamanan (Safety Stock)

Persedian pengaman adalah persedian tambahan yang diadakan untuk mengantisipasi atau menjaga kemungkinan bila terjadi kekurangan atau kehabisan bahan baku. Persedian pengaman dapat mengurangi kerugian akibat kekurangan persedian, tetapi disisi lain persedian pengaman dapat menambah biaya penyimpanan bahan baku Dalam Perhitungan safety stock adalah sebagai berikut:

$$
\mathrm{SD}=\sqrt{\frac{\sum(X-\bar{X})^{2}}{N}}
$$

Keterangan :

$\mathrm{SD}=$ Standar Deviasi

$\mathrm{X}=$ Pemakaian Sesunguhnya

$\bar{X}=$ Perkiran Pemakaian

$\mathrm{N}=$ Jumlah Data

Safety Stock = Standar Deviasi $\mathrm{x}(\mathrm{Z})$

Keterangan :

SS = Persedian Pengaman (Safety Stock)

$\mathrm{SD}=$ Standar Deviasi

$\mathrm{Z}=$ Faktor Keamanan yang ditentukan atas kemampuan perusahan

e. Pemesanan Ulang (Reorder Point)

Pemesanan ulang ditentukan berdasarkan kebutuhan selama tenggang waktu pemesanan. Jika posisi persediaan cukup untuk memenuhi permintaan selama tenggang waktu pemesanan, maka pemesanan ulang harus dilakukan sebanyak Q unit atau EOQ. sehingga pemesanan ulang bisa dihitung dengan menggunakan perhitungan :

$$
\mathrm{ROP}=\mathrm{L} \times \mathrm{D} . \mathrm{L}
$$


Dimana :

ROP $=$ Titik pemesanan ulang (Reorder Point $)$

$\mathrm{LT}=$ Waktu tunggu (lead time)

$\mathrm{D}=$ Jumlah Permintaan

\section{HASIL DAN PEMBAHASAN}

3.1 Pengumpulan Data

3.1.2 Persediaan Bahan Baku Kondisi Perusahan Saat ini

Dalam hal ini bahan baku Consumable yang digunakan dalam kegiatan inspeksi MPI (Magnetic Particle Inspection) ini yaitu WCP-2 dan 7HF. Perusahan memiliki kebijakan dalam menuntukan persedian bahan baku tanpa menggunakan metode Economic Order Quantity (EOQ),Berikut tabel bahan baku persediaan Consumble ini.

Tabel 1. Persedian Bahan Consumable WCP-2 Tahun 2017

\begin{tabular}{|c|c|c|}
\hline No & $\begin{array}{l}\text { Persediaan } \\
\text { Bulan }\end{array}$ & $\begin{array}{l}\text { Periode Persediaan Bahan Cosumable Periode } \\
\text { Tahun } 2017 \text { White Contrast Paint (WCP-2) }\end{array}$ \\
\hline 1 & January & 288 \\
\hline 2 & February & 204 \\
\hline 3 & Maret & 222 \\
\hline 4 & April & 232 \\
\hline 5 & May & 242 \\
\hline 6 & June & 234 \\
\hline 7 & July & 218 \\
\hline 8 & Agustus & 236 \\
\hline 9 & September & 242 \\
\hline 10 & Oktober & 240 \\
\hline 11 & November & 216 \\
\hline 12 & Desember & 242 \\
\hline \multicolumn{2}{|r|}{ Jumlah } & 2,816 \\
\hline \multicolumn{2}{|r|}{ Rata-rata } & 235 \\
\hline
\end{tabular}

Pada table $4.2 \mathrm{di}$ atas menerangkan bahwa PT. Sucofindo Batam telah melakukan Persediaan bahan consumable White Contarst Paint (WCP-2) pada tahun 2017 berjumlah 2,816 can, dengan rat-rat perbulan sebesar 235 cans dan bahan baku ini dipesan PT. Sucofindo dari supplier PT. Pratita Prama Nugraha di daerah Batam Center - Batam (Peta) yang telah menjadi rekanan selama ini.

Tabel 2. Persediaan Bahan Consumable Back Ink (7HF) Tahun 2017

\begin{tabular}{|c|l|c|}
\hline \multirow{2}{*}{ No } & \multirow{2}{*}{$\begin{array}{c}\text { Persediaan } \\
\text { Bulan }\end{array}$} & $\begin{array}{c}\text { Periode Persediaan Bahan Cosumable Periode } \\
\text { Tahun 2017 Black Ink (7HF) }\end{array}$ \\
\cline { 3 - 3 } & & $\mathbf{7 H F}$ \\
\hline 1 & January & 144 \\
\hline 2 & February & 102 \\
\hline 3 & Maret & 111 \\
\hline 4 & April & 116 \\
\hline 5 & May & 121 \\
\hline 6 & June & 117 \\
\hline 7 & July & 109 \\
\hline 8 & Agustus & 118 \\
\hline 9 & September & 121 \\
\hline 10 & Oktober & 120 \\
\hline 11 & November & 108 \\
\hline
\end{tabular}




\begin{tabular}{|c|l|c|}
\hline 12 & Desember & 121 \\
\hline \multicolumn{2}{|c|}{ Jumlah } & 1.408 \\
\hline \multicolumn{2}{|c|}{ Rata-rata } & 117 \\
\hline \multicolumn{2}{|c|}{ Sumber : Doc PT.Sucofindo }
\end{tabular}

Pada tabel 2 di atas menerangkan bahwa PT. Sucofindo Batam telah melakukan Persediaan bahan consumable Black Ink 7HF pada tahun 2017 berjumlah 1,408 cans, dengan rat-rat perbulan sebesar 117 cans dan bahan baku ini dipesan PT. Sucofindo dari supplier PT. Pratita Prama Nugraha di daerah Batam Center - Batam (Peta) yang telah menjadi rekanan selama ini.

\subsubsection{Biaya Pemesanan}

Untuk biaya pemesanan bahan baku WCP-2 dan 7HF dalam sekali pemesanan terdiri dari bebrapa biaya pada periode tahun 2017 yaitu :

a. Biaya Telpon

Biaya telpon yang di keluarkan oleh PT. Sucofindo Batam untuk melakukan sekali pemesanan bahan baku adalah :

$$
\begin{aligned}
\text { Biaya Telpon } & =\text { Tarif } x \text { Waktu } \\
& =\text { Rp. } 250 \text { per menit x } 45 \text { menit } \\
& =\text { Rp. } 11.250
\end{aligned}
$$

b. Upah Karyawan

Dalam melakukan perhitungan upah karyawan untuk pemesanan bahan baku WCP-2 dan 7HF, PT. Sucofindo yaitu :

Upah

$=$ Gaji perbulan $\mathrm{x}$ Jumlah karyawan $\mathrm{x}$ aktivitas order $30 \%$

$=$ Rp. $3.150 .000 \times 1$ orang penjaga gudang $\times 30 \%$

$=$ Rp. 945.000

c. Biaya Administrasi

Dalam perhitungan biaya administrasi, PT. Sucofindo Batam memperhitungkan dari biaya kertas dan tinta, adapun biayanya sebagai berikut :

$$
\begin{aligned}
\text { Biaya kertas } & =\text { Rp. } 38.900 \text { per } 500 \text { pcs } / 180 \mathrm{pcs} \\
& =\text { Rp. } 216.10 \\
\text { Biaya Tinta } & =\text { Rp. } 160.000 \text { per } 1 \text { botol } / 430 \mathrm{pcs} \\
& =\text { Rp. } 372.09 \\
\text { Biaya Internet } & =\text { Rp. } 2.500 \text { per jam x } 30 \text { menit } \\
& =\text { Rp. } 75.000
\end{aligned}
$$

Total biaya Administrasi adalah Biaya Kertas + Biaya Tinta + Biaya Internet.

Total Biaya $=$ Rp. $216.00+$ Rp. $372.09+$ Rp. 75.000

d. Biaya Trasportasi

$$
=\text { Rp. } 75.588 .09
$$

Untuk biaya trasportasi mengunakan jasa dari Koperasi Bahtera dan harga sudah disepakati bersama antara PT. Sucofindo Batam dengan Koperasi Bahtera Batam. Adapun biaya transportasi dalam kontrak bersama sebesar Rp. 10.000.000 dalam setahun di bagi 12 bulan, jadi biaya transportasi sekali pemesanan sebesar Rp. 830.000.

Tabel 3. Tabel Biaya Pemesanan

\begin{tabular}{|c|l|c|}
\hline \multirow{2}{*}{ No } & \multicolumn{1}{|c|}{ Jenis Biaya } & Biaya Per Pesanan \\
\cline { 3 - 3 } & & WCP-2 \& 7HF Periode 2017 \\
\hline 1 & Biaya Telpon & Rp. 11.250 \\
\hline 2 & Upah Karyawan & Rp. 945.000 \\
\hline 3 & Biaya Administrasi & Rp. 75.588 \\
\hline 4 & Biaya Trasnportasi & Rp. 830.000 \\
\hline Jumlah & Rp. 1.861 .838 \\
\hline
\end{tabular}




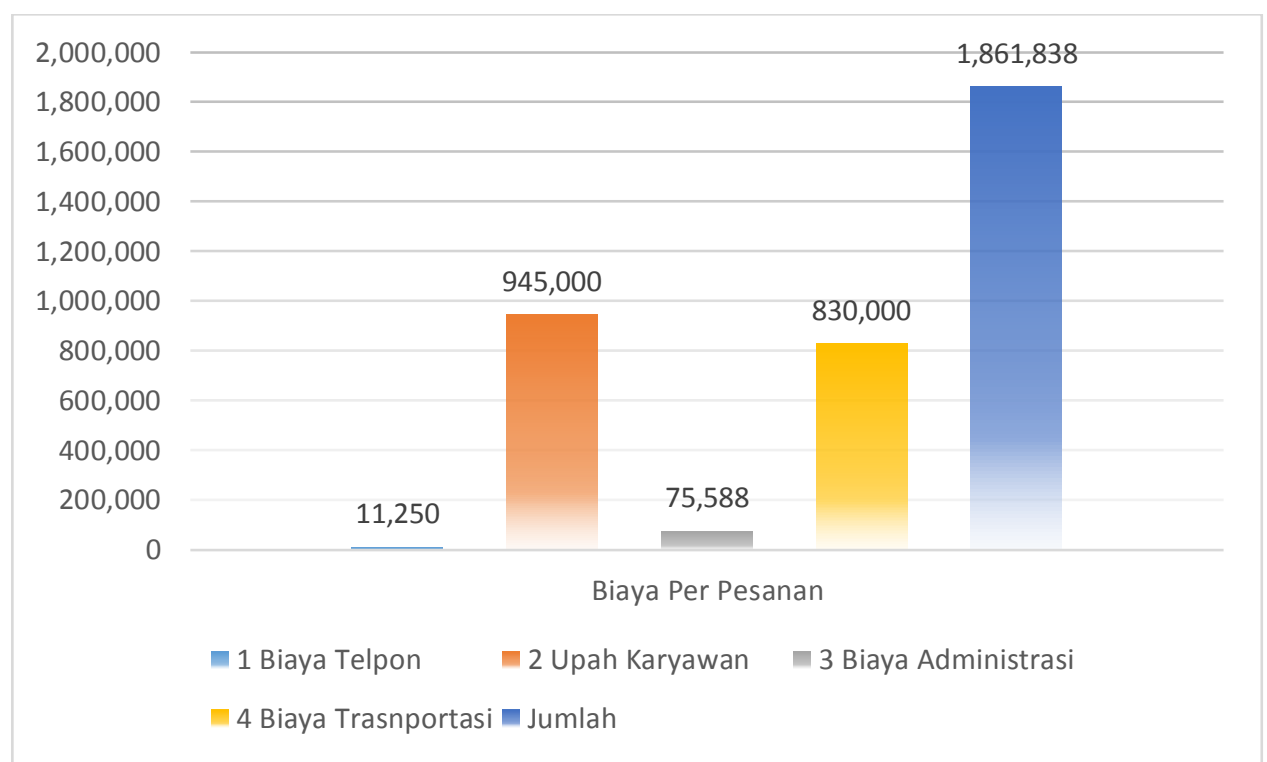

Gambar 1. Diagram Colloum Total Biaya Pemesanan

\subsubsection{Biaya Penyimpanan}

Dalam biaya penyimpanaan yang telah ditetapkan oleh PT. Sucofindo Batam untuk perhitungan akan dikalikan dengan harga bahan baku dan waktu selama 12 bulan dapat dilihat dibawah ini:
Biaya Penyimpan $\quad=0.35 \% \times$ Harga bahan baku $\times 12$ bulan $=0.35 \%$ x Rp. 90.000 per cans $\times 12$ bulan$$
=\text { Rp. } 3.780 \text { per cans per tahun }
$$

\subsubsection{Total Biaya Persedian WCP-2 Kebijakan PT. Sucofindo Batam}

Total biaya persediaan di hitung dari total jumlah Cosumable WCP2, adapun data di uraikan sebagai berikut :

a. Total kebutuhan bahan baku WCP-2 = 2.816 cans

b. Biaya Pemesanan Per sekali pesan Rp. 1.861 .838

c. Biaya Penyimpanan Rp. 3.780 per cans

d. Harga bahan baku Rp. 90.000

Dari data di atas PT. Sucofindo Batam melakukan kebijakan perhitungan bahan baku WCP-2 yang mana akan di asumsikan kedalam perhitungan di bawah ini :

$$
\begin{aligned}
& \text { TC = (biaya pemesanan per pesan } \mathrm{x} \text { jumlah pemesanan })+ \\
& \text { (biaya penyimpanan per cans } \mathrm{x} \text { jumlah bahan baku) }+ \\
& \text { (jumlah bahan baku + harga bahanbaku per cans) } \\
& \mathrm{TC}=(\text { Rp. } 1.861 .838 \times 12 \mathrm{kali})+(\text { Rp. } 3.780 \times 2.816)+ \\
& \text { (2.816 x Rp. 90.000) } \\
& \text { TC }=\text { Rp. } 22.342 .056+\text { RP.10.644.480 + Rp. } 253.440 .000 \\
& \mathrm{TC} \quad=\text { Rp. } 286.426 .536
\end{aligned}
$$

Jadi PT. Sucofindo Batam melakukan pemesanan persedian bahan baku WCP-2 dalam periode tahun 2017 sebesar Rp. 286.426.536

\subsubsection{Total Biaya Persedian 7HF Kebijakan PT. Sucofindo Batam}

Total biaya persediaan di hitung dari total jumlah Cosumable 7HF, adapun data di uraikan sebagai berikut :

a. Total kebutuhan bahan baku $7 \mathrm{HF}=1.408$ cans

b. Biaya Pemesanan Per sekali pesan Rp. 1.861 .838

c. Biaya Penyimpanan Rp. 3.780 per cans

d. Harga bahan baku Rp. 90.000 
Dari data di atas PT. Sucofindo Batam melakukan kebijakan perhitungan bahan baku 7HF yang mana akan di asumsikan kedalam perhitungan di bawah ini :

$$
\begin{aligned}
\mathrm{TC}= & (\text { biaya pemesanan per pesan } \mathrm{x} \text { jumlah pemesanan })+ \\
\text { (biaya penyimpanan per cans } \mathrm{x} \text { jumlah bahan baku) }+ & \quad \\
& \text { (jumlah bahan baku }+ \text { harga bahanbaku per cans }) \\
\mathrm{TC}= & (\mathrm{Rp} .1 .861 .838 \times 12 \mathrm{kali})+(\mathrm{Rp} .3 .780 \times 1.408)+ \\
& (1.408 \times \mathrm{Rp} .90 .000) \\
\mathrm{TC} \quad= & \text { Rp. } 22.342 .056+\text { RP.5.322.240 + Rp. } 126.720 .000 \\
\mathrm{TC} \quad= & \text { Rp. } 154.384 .296
\end{aligned}
$$

Jadi PT. Sucofindo Batam melakukan pemesanan persedian bahan baku 7HF dalam periode tahun 2017 sebesar Rp. 154.384 .296

\subsection{Pengolahan Data}

Pengolahan data merupakan bagian yang amat penting dalam metode ini, karena data tersebut dapat berguna dalam memecahkan masalah penelitian dengan mengunakan penerapan metode Economic Order Quantity (EOQ)

\subsection{Analisa Mengunakan Metode Economic Order Quantity}

\subsubsection{Perhitungan Pemesanan Bahan Baku WCP-2 Metode EOQ}

Perhitungan EOQ akan dilandasi pada data data yang telah di perhitungan oleh hasil dari perhitungan di atas. Berikut rincian biaya yang telah di perhitungan di atas sebagai berikut:

a. Total kebutuhan bahan baku WCP-2

$$
\mathrm{D}=2.816 \text { cans }
$$

b. Biaya Pemesanan Per sekali pesan

$$
\mathrm{S}=\mathrm{Rp} .1 .861 .838
$$

c. Biaya Penyimpanan

$$
\mathrm{H}=\mathrm{Rp} .3 .780 \text { per cans }
$$

d. Harga bahan baku Rp. 90.000

Rumus yang di gunakan sebagai berikut :

$$
E O Q=\sqrt{\frac{2 . D . S}{h}}
$$

Keterangan :

$\mathrm{D}=$ Total Kebutuhan Bahan Baku

$\mathrm{S}=$ Biaya Pemesanan

$\mathrm{h}=$ Biaya Penyimpanan

Maka, besarnya pemesanan bahan baku yang ekonomis menurut metode EOQ adalah sebagai berikut :

$$
E O Q=\sqrt{\frac{2 \times R p .2 .816 \times 1.861 .838 \text { cans }}{R p .3 .780}}
$$

$\mathrm{EOQ}=1.665 .5$ cans dibulatkan menjadi 1.666 cans

Dari perhitungan di atas bahwa total pemesanan bahan baku WCP-2 yang ekonomis atau yang optimal sebanyak 1.666 cans.

3.3.2 Frekuensi Pemesanan Bahan Baku WCP-2

Dalam pemesanan bahan baku dengan mengunakan metode EOQ dapat di cari nilai persamaannya sebagai barikut :

Keterangan :

$$
F=\frac{D}{E O Q}
$$

$\mathrm{D}=$ Total Kebutuhan Bahan Baku 
$\mathrm{EOQ}=$ Nilai EOQ

$$
\begin{aligned}
F & =\frac{2.816}{1.666} \\
F & =1.69 \text { dibulatkan } 2 \text { kali }
\end{aligned}
$$

Dari perhitungan di atas menunjukan bahwa untuk frekuensi pemesanan bahan baku WCP-2 seharusnya dilakukan sebanyak 2 kali.

3.3.3 Total Biaya Persediaan Bahan Baku WCP-2

Untuk total biaya persediaan telah di ketahui harga bahan baku per cans sebesar Rp. 90.000 per cans.

$$
T C=D \cdot P+\frac{D}{Q} S+\frac{Q}{2} H
$$

Keterangan :

$$
\begin{aligned}
\mathrm{D} & =\text { Total Kebutuhan Bahan Baku } \\
\mathrm{P} & =\text { Harga Bahan Baku } \\
\mathrm{Q} & =\text { Nilai EOQ } \\
\mathrm{S} & =\text { Biaya Pemesanan } \\
\mathrm{h} & =\text { Biaya Penyimpanan } \\
\mathrm{TC} & =2.816 \text { cans } x \text { Rp. } 90.000+\frac{2.816}{1.666} \times 1.861 .838+\frac{2.816}{2} \times R p .3 .780 \\
\mathrm{TC} & =253.440 .000+3.147 .020+5.322 .240 \\
\mathrm{TC} & =\text { Rp. } 261.909 .260
\end{aligned}
$$

Dengan metode EOQ, dapat di temukan biaya total yang di keluarkan oleh PT. Sucofindo Batam untuk pemesanan bahan baku WCP-2 pada periode tahun 2017 sebesar Rp. 261.909.260.

3.3.4 Perhitungan Safety Stock WCP-2

Dalam mencari safety stock, akan di gunakan perhitungan standar deviasi dengan mengunakan persamaan, dan perlu dilakukan perbandingan antara kebutuhan bahan baku dengan rata-rata pegunaan bahan baku yang kemudian aan di cari penyimpangannya. Adapaun table standar deviasi akan di uraikan di bawah ini.

Tabel 4. Tabel Satndar Deviasi Bahan Baku WCP-2

\begin{tabular}{|l|c|c|c|c|}
\hline \multicolumn{1}{|c|}{ Bulan } & $\begin{array}{c}\text { Kebutuhan Bahan } \\
\text { Baku WCP-2 }\end{array}$ & $\bar{X}$ & $(\mathbf{X}-\mathbf{X b a r})$ & $\left(\mathbf{X}-\mathbf{X b a r}^{\mathbf{2}}\right.$ \\
\hline January & 288 & 235 & 53 & 2.809 \\
\hline February & 204 & 235 & -31 & 961 \\
\hline Maret & 222 & 235 & -13 & 169 \\
\hline April & 232 & 235 & -3 & 9 \\
\hline May & 242 & 235 & 7 & 49 \\
\hline June & 234 & 235 & -1 & 1 \\
\hline July & 218 & 235 & -17 & 289 \\
\hline Agustus & 236 & 235 & 1 & 1 \\
\hline September & 242 & 235 & 7 & 49 \\
\hline Oktober & 240 & 235 & 5 & 25 \\
\hline November & 216 & 235 & -19 & 361 \\
\hline Desember & 242 & 235 & 7 & 49 \\
\hline Total & $\mathbf{2 . 8 1 6}$ cans & & Total & $\mathbf{4 . 7 7 2}$ \\
\hline
\end{tabular}

Dari data di atas dapat di ketahui jumlah dari $(\mathrm{X}-\mathrm{X})^{2}$ adalah 4.772 , jadi standar deviasi dapat di hitung dengan memasukan rumus di bawah ini :

Keterangan :

SD

$\mathrm{SD}=$ Standar Deviasi

$$
=\sqrt{\frac{\Sigma(X-\bar{X})^{2}}{N}}
$$

$X=$ Pemakaian Sesunguhnya

$\bar{X}=$ Perkiran Pemakaian 


$$
\begin{aligned}
\mathrm{N}=\text { Jumlah Data } & \\
S D & =\frac{\sqrt{4.772}}{12} \\
S D & =\sqrt{69.079 .664} \\
S D & =19.94 \text { dibulatkan menajdi } 20 \text { cans }
\end{aligned}
$$

Penentuan Persediaan Pengaman (Safety Stock) berguna untuk melindungi perusahaan dari resiko kehabisan bahan baku (Stock Out) dan keterlambatan penerimaan bahan baku yang dipesan. Setelah diketahui berapa besarnya standar deviasi masing - masing tahun maka akan ditetapkan besarnya analisis penyimpangan. Dalam analisis penyimpangan ini management perusahaan menentukan seberapa jauh bahan baku yang masih dapat diterima dengan toleransi yang digunakan adalah 5\% diatas perkiraan dan 5\% dibawah perkiraan dengan nilai $\mathrm{Z}$ dalam table sebesar 1.65. Untuk perhitungan standar deviasi di atas rata rata.

$$
\begin{aligned}
\text { Safety Stock } & =\mathrm{SD} \times \mathrm{Z} \\
& =20 \text { cans } \times 1.65 \\
& =33 \text { cans }
\end{aligned}
$$

Jadi persediaan safety stock yang harus disediakan oleh PT. Sucofindo Batam untuk bahan baku WCP-2 sebesar 33 cans.

\subsubsection{Perhitungan Reorder Point WCP-2}

Untuk rumus yang digunakan perhitungan ROP akan ditentukan pada saat nilai $\mathbf{t}$ telah ditemukan maka akan membantu dalam perhitungan nilai $\mathbf{t}$ yaitu:

Keterangan :

$$
\mathrm{t}=\mathrm{Q} / \mathrm{D}
$$

$$
\begin{aligned}
& \mathrm{t}=\text { Siklus waktu pemesanan } \\
& \mathrm{Q}=\text { Nilai EOQ } \\
& \begin{array}{l}
\mathrm{D}=\text { Jumlah permintaan } \\
\mathrm{t}=(\mathrm{Q} / \mathrm{D}) .12 \\
\mathrm{t}=(1,666 / 2,816) \times 12 \\
\mathrm{t}=0.59 \times 12 \\
\mathrm{t}=7.09 \text { bulan }
\end{array}
\end{aligned}
$$

Dari hasil perhitungan di atas menunjukan bahwa nilai $\mathbf{t}$ - Lead time atau waktu tunggu dimana perusahaan melakukan pemesanan bahan bakunya kembali dengan waktu tunggu 7 hari atau sekitar 0.23 bulan. Dan di ketahui bahwa nila $\mathrm{L}<\mathrm{t}$, Karena dalam melakukan pemesanan bahan baku tidak dapat langsung diterima hari itu juga. Maka perhitungan dari nilai ROP akan dapat di hitung:

$$
\begin{aligned}
& \text { Keterangan : } \\
& \mathrm{D}=\text { Tingkat Kebutuhan Bahan Baku } \\
& \mathrm{L}=\text { Waktu Tunggu } \\
& \mathrm{ROP}=0.23 \times 2.816 \times 0.23 \\
& \mathrm{ROP}=148.9 \text { cans } \\
& \text { ROP }=148.9 \text { cans dibulatkan menjadi } 149 \text { cans }
\end{aligned}
$$

Hasil dari perhitungan menunjukna bahwa titik pemesanan kembalibahan baku agar perusahaan tidak mengalami kehabisan bahan baku WCP2 adalah sebesar 149 cans.

\subsubsection{Perhitungan Persedian Bahan Baku 7HF Metode EOQ}

Perhitungan EOQ akan dilandasi pada data-data yang telah di perhitungan oleh hasil dari perhitungan di atas. Berikut rincian biaya yang telah di perhitungan di atas sebagai berikut:

e. Total kebutuhan bahan baku 7HF 
f. Biaya Pemesanan Per sekali pesan

$\mathrm{S}=\mathrm{Rp} .1 .861 .838$

g. Biaya Penyimpanan

$\mathrm{H}=$ Rp. 3.780 per cans

h. Harga bahan baku Rp. 90.000

Rumus yang di gunakan sebagai berikut :

$$
E O Q=\sqrt{\frac{2 \cdot D \cdot S}{h}}
$$

Keterangan :

$\mathrm{D}=$ Total Kebutuhan Bahan Baku

$\mathrm{S}=$ Biaya Pemesanan

$\mathrm{h}=$ Biaya Penyimpanan

Maka, besarnya pemesanan bahan baku yang ekonomis menurut metode EOQ adalah sebagai berikut :

$$
E O Q=\sqrt{\frac{2 \times R p .1 .408 \times 1.861 .838 \text { cans }}{R p .3 .780}}
$$

$\mathrm{EOQ}=1.177 .7$ cans dibulatkan menjadi 1.178 cans

Dari perhitungan di atas bahwa total pemesanan bahan baku 7HF yang ekonomis atau yang optimal sebanyak 1.178 cans.

3.3.7 Frekuensi Pemesanan Bahan Baku 7HF

Dalam pemesanan bahan baku dengan mengunakan metode EOQ dapat di cari nilai persamaannya sebagai barikut :

$$
F=\frac{D}{E O Q}
$$

Keterangan :

$\mathrm{D}=$ Total Kebutuhan Bahan Baku

$\mathrm{EOQ}=$ Nilai EOQ

$$
\begin{aligned}
F & =\frac{1.408}{1.178} \\
F & =1.19 \text { dibulatkan } 1 \mathrm{kali}
\end{aligned}
$$

Dari perhitungan di atas menunjukan bahwa untuk frekuensi pemesanan bahan baku 7HF seharusnya dilakukan sebanyak 1 kali.

3.3.8 Total Biaya Persediaan 7HF

Untuk total biaya persediaan telah di ketahui harga bahan baku per cans sebesar Rp. 90.000 per cans.

$$
T C=D \cdot P+\frac{D}{Q} S+\frac{Q}{2} H
$$

Keterangan :

$\mathrm{D}=$ Total Kebutuhan Bahan Baku

$\mathrm{P}=$ Harga Bahan Baku

$\mathrm{Q}=$ Nilai EOQ

$\mathrm{S}=$ Biaya Pemesanan

$\mathrm{h}=$ Biaya Penyimpanan

$$
\begin{aligned}
& \mathrm{TC}=1.408 \text { cans } x \text { Rp. } 90.000+\frac{1.408}{1.178} \times 1.861 .838+\frac{1.178}{2} \times R p .3 .780 \\
& \mathrm{TC}=126.720 .000+2.225 .354+2.226 .420 \\
& \mathrm{TC}=\text { Rp. } 131.171 .774
\end{aligned}
$$


Dengan metode EOQ, dapat di temukan biaya total yang di keluarkan oleh PT. Sucofindo Batam untuk pemesanan bahan baku 7HF pada periode tahun 2017 sebesar Rp. 131.171.774

3.3.9 Perhitungan Safety Stock 7HF

Dalam mencari safety stock, akan di gunakan perhitungan standar deviasi dengan mengunkan persamaan, dan perlu dilakukan perbandingan antara kebutuhan bahan baku dengan rata-rata pegunaan bahan baku yang kemudian aan di cari penyimpangannya. Adapaun table standar deviasi akan di uraikan di bawah ini.

Tabel 5. Tabel Satndar Deviasi Bahan Baku 7HF

\begin{tabular}{|l|c|c|c|c|}
\hline \multicolumn{1}{|c|}{ Bulan } & $\begin{array}{c}\text { Kebutuhan Bahan Baku } \\
\mathbf{7 H F}\end{array}$ & $\mathbf{X}$ & $(\mathbf{X}-\overline{\mathbf{X}})$ & $(\mathbf{X}-\overline{\mathbf{X}})^{\mathbf{2}}$ \\
\hline January & 144 & 117 & 27 & 729 \\
\hline February & 102 & 117 & -15 & 225 \\
\hline Maret & 111 & 117 & -6 & 36 \\
\hline April & 116 & 117 & -1 & 1 \\
\hline May & 121 & 117 & 4 & 16 \\
\hline June & 117 & 117 & 0 & 0 \\
\hline July & 109 & 117 & -8 & 64 \\
\hline Agustus & 118 & 117 & -1 & 1 \\
\hline September & 121 & 117 & 4 & 16 \\
\hline Oktober & 120 & 117 & 3 & 9 \\
\hline November & 108 & 117 & -9 & 81 \\
\hline Desember & 121 & 117 & 4 & 16 \\
\hline Total & $\mathbf{1 . 4 0 8}$ cans & & Total & $\mathbf{1 . 1 9 4}$ \\
\hline
\end{tabular}

Dari data di atas dapat di ketahui jumlah dari $(\mathrm{X}-)^{2}$ جalah 1.194 jadi standar deviasi dapat di hitung dengan memasukan rumus di bawah ini :

$$
\begin{aligned}
& \text { Keterangan : } \quad \mathrm{SD}=\sqrt{\frac{\sum(X-\bar{X})^{2}}{N}} \\
& \text { SD = Standar Deviasi } \\
& \mathrm{X}=\text { Pemakaian Sesunguhnya } \\
& \bar{X}=\text { Perkiran Pemakaian } \\
& \mathrm{N}=\text { Jumlah Data } \\
& \qquad \begin{aligned}
S D & =\frac{\sqrt{1.194}}{12} \\
S D & =\sqrt{34.554 .305} \\
S D & =9.97 \text { dibulatkan menajdi } 10 \text { cans }
\end{aligned}
\end{aligned}
$$

Penentuan Persediaan Pengaman (Safety Stock) berguna untuk melindungi perusahaan dari resiko kehabisan bahan baku (Stock Out) dan keterlambatan penerimaan bahan baku yang dipesan. Setelah diketahui berapa besarnya standar deviasi masing-masing tahun maka akan ditetapkan besarnya analisis penyimpangan. Dalam analisis penyimpangan ini management perusahaan menentukan seberapa jauh bahan baku yang masih dapat diterima dengan toleransi yang digunakan adalah 5\% diatas perkiraan dan 5\% dibawah perkiraan dengan nilai $\mathrm{Z}$ dalam table sebesar 1.65. Untuk perhitungan standar deviasi di atas rata rata.

$$
\begin{aligned}
\text { Safety Stock } & =\mathrm{SD} \times \mathrm{Z} \\
& =10 \text { cans } \mathrm{x} 1.65 \\
& =16.5 \text { cans dibulatkan menjadi } 17
\end{aligned}
$$


Jadi persediaan safety stock yang harus disediakan oleh PT. Sucofindo Batam untuk bahan baku 7HF sebesar 17 cans.

\subsubsection{Perhitungan Reorder Point 7HF}

Untuk rumus yang digunakan perhitungan ROP akan ditentukan pada saat nilai $\mathbf{t}$ telah ditemukan maka akan membantu dalam perhitungan nilai $\mathbf{t}$ yaitu:

Keterangan :

$$
\mathrm{t}=\mathrm{Q} / \mathrm{D}
$$

$\mathrm{t}=$ Siklus waktu pemesanan

$\mathrm{Q}=$ Nilai EOQ

$\mathrm{D}=$ Jumlah permintaan

$$
\begin{aligned}
& t=(Q / D) \cdot 12 \\
& t=(1,178 / 1.408) \times 12 \\
& t=0.83 \times 12
\end{aligned}
$$

Dari hasil perhitungan di atas menunjukan bahwa nilai $\mathbf{t}$ - Lead time atau waktu tunggu dimana perusahaan melakukan pemesanan bahan bakunya kembali dengan waktu tunggu 7 hari atau sekitar 0.23 bulan. Dan di ketahui bahwa nila $\mathbf{L}<\mathbf{t}$, Karena dalam melakukan pemesanan bahan baku tidak dapat langsung diterima hari itu juga. Maka perhitungan dari nilai ROP akan dapat di hitung:

$$
\begin{aligned}
& \quad \mathrm{ROP}=\mathrm{L} \times \mathrm{D} . \mathrm{L} \\
& \text { Keterangan : } \\
& \mathrm{D}=\text { Tingkat Kebutuhan Bahan Baku } \\
& \mathrm{L}=\text { Waktu Tunggu } \\
& \mathrm{ROP}=0.23 \times 1.408 \times 0.23 \\
& \mathrm{ROP}=74.4 \text { cans } \\
& \text { ROP }=74 \text { cans }
\end{aligned}
$$

Hasil dari perhitungan menunjukan bahwa titik pemesanan kembali bahan baku agar perusahaan tidak mengalami kehabisan bahan baku adalah sebesar 74 cans.

3.3.11 Perbandingan Perhitungan Kebijakan Perusahaan dengan Metode Economic Order Quantity EOQ

Persediaan bahan baku adalah barang-barang yang dibeli atau diperoleh dari sumber lain, persediaan bahan baku yang digunakan di dalam Inspeksi yang di lakukan PT. Sucofindo Cabang Batam berupa bahan coosumable WCP-2 dan 7HF. Dalam hal ini, persediaan bahan baku seringkali disebut sebagai persediaan suku cadang. Untuk mengetahui lebih jelas mengenai perhitungan perbandingan persediaan Consumable bahan baku di PT. Sucofindo Cabang Batam dengan menggunakan metode EOQ selama periode tahun 2017 dapat dilihat pada Table di bawah ini.

Tabel 6. Perbandingan Perhitungan WCP-2 Kebijakan Perusahanan dengan Metode EOQ 2017

\begin{tabular}{|l|l|c|c|c|}
\hline \multicolumn{5}{|c|}{$\begin{array}{r}\text { Perbandingan Perhitungan Kebijakan Perusahanan dengan Metode EOQ } \\
\text { Bahan Baku WCP-2 Periode Tahun 2017 }\end{array}$} \\
\hline No. & \multicolumn{1}{|c|}{ Keterangan } & $\begin{array}{c}\text { Kebijkan } \\
\text { Perusahaan }\end{array}$ & Metode EOQ & Penghematan \\
\hline 1 & $\begin{array}{l}\text { Pemesanan Rata- } \\
\text { rata bahan baku }\end{array}$ & 235 & 1.666 & - \\
\hline 2 & Total Cost & Rp. 286.426.536 & Rp. 261.909.260 & Rp. 24.517.276 \\
\hline 3 & $\begin{array}{l}\text { Frekuensi } \\
\text { Pemesanan }\end{array}$ & 12 kali & 2 kali & \\
\hline 4 & Safety Stock & - & 33 cans & \\
\hline
\end{tabular}




\begin{tabular}{|l|l|l|l|l|}
\hline 5 & Reorder Point & - & 149 cans & \\
\hline
\end{tabular}

Berdasarkan hasil dari perbandingan di atas bahwa jika perusahan menerapkan Metode EOQ dalam pembelian bahan baku WCP-2 pada periode tahun 2017, maka perusahan akan hemat sebesar $8,6 \%$ dalam setahun.

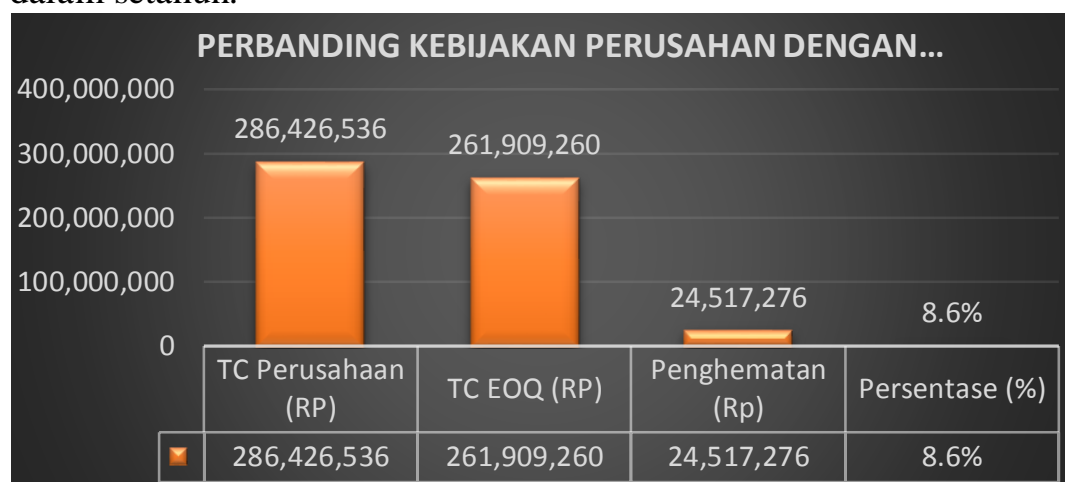

Gambar 2. Diagram Colloum Perhitungan WCP-2 Metode EOQ

Tabel 7. Perbandingan Perhitungan 7HF Kebijakan Perusahanan dengan Metode EOQ 2017

\begin{tabular}{|l|l|c|c|c|}
\hline \multicolumn{5}{|c|}{$\begin{array}{r}\text { Perbandingan Perhitungan Kebijakan Perusahanan dengan Metode EOQ } \\
\text { Bahan Baku 7HF Periode Tahun 2017 }\end{array}$} \\
\hline No. & \multicolumn{1}{|c|}{ Keterangan } & $\begin{array}{c}\text { Kebijkan } \\
\text { Perusahaan }\end{array}$ & $\begin{array}{c}\text { Usulan Metode } \\
\text { EOQ }\end{array}$ & Penghematan \\
\hline 1 & $\begin{array}{l}\text { Pemesanan Rata- } \\
\text { rata bahan baku }\end{array}$ & 117 & 1.178 & - \\
\hline 2 & Total Cost & Rp. 154.384 .296 & Rp. 131.171.774 & Rp. 23.212.522 \\
\hline 3 & $\begin{array}{l}\text { Frekuensi } \\
\text { Pemesanan }\end{array}$ & 12 kali & 1 kali & \\
\hline 4 & Safety Stock & - & 17 cans & \\
\hline 5 & Reorder Point & - & 74 cans & \\
\hline
\end{tabular}

Berdasarkan hasil dari perbandingan di atas bahwa jika perusahan menerapkan Metode EOQ dalam pembelian bahan baku 7HF pada periode tahun 2017, maka perusahan akan hemat sebesar $15 \%$ dalam setahun.

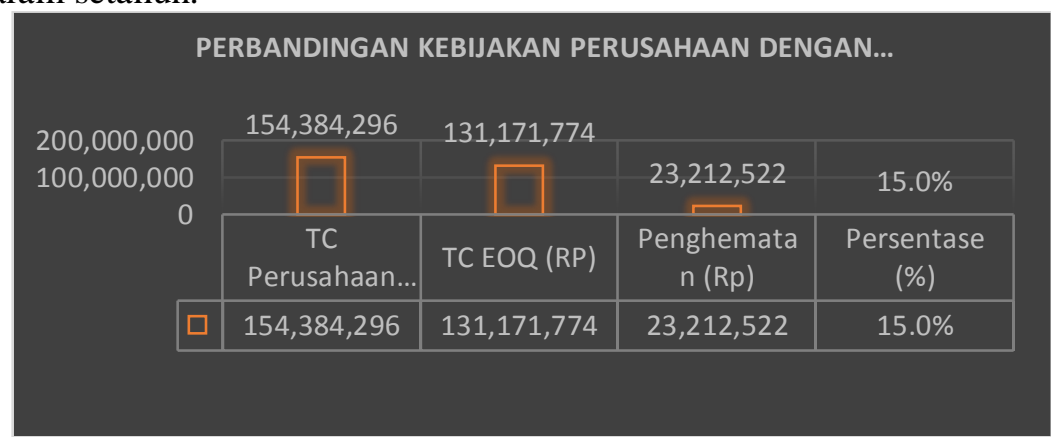

Gambar 3. Diagram Colloum Perhitungan 7HF Metode EOQ

\subsection{Analisa dan Pembahasan}

Dari hasil perhitungan di atas terlihat perbandingan total biaya persediaan menggunakan Metode Economic Order Quality (EOQ) dapat termonitor dan terkontrol, serta lebih hemat dibandingkan dengan hasil perhitungan total biaya persediaan yang dilakukan oleh perusahaan. PT. Sucofindo Batam mengeluarkan biaya pemesanan bahan baku untuk WCP-2 sebesar Rp. 286.426.536, sedangkan dengan perhitungan metode EOQ biaya pemesanan bahan baku menajdi 
sebesar Rp. 261.909.260, maka dengan ini perusahaan akan lebih hemat sebesar Rp. 24.517.276 atau sekitar $8.6 \%$. Sedangkan untuk pemesanan bahan baku 7HF PT. Sucofindo Batam mengeluarkan biaya pemesanan sebesar Rp. 154.384.296, sedangkan dengan metode EOQ biaya pemesanan bahan baku menajdi sebesar Rp. 131.171.774, maka dengan ini perusahaan akan lebih hemat sebesar RP.23.212.522 atau sekitar 15\%.

Perhitungan EOQ dapat menentukan besarnya safety stock untuk menghitung ROP dan persediaan Safety Stock merupakan persediaan pengaman. Persediaan ini bisa menghindari resiko kekurangan stock (stock out) jika suatu waktu persediaan bahan baku telah habis tidak sesuai dengan yang direncanakan karena ada sesuatu dan lain hal pada perusahaan. Perhitungan safety stock telah didapat, maka penentuan pesanan kembali (reorder point) bisa ditentukan karena ROP didapat dari hasil penggunaan selama waktu tunggu pesanan (lead time). Selanjutnya perusahaan melakukan perhitungan TC, yaitu total cost (total biaya persediaan). Dari hasil yang didapat, TC oleh metode EOQ lebih hemat dari hasil TC oleh perusahaan.

\section{KESIMPULAN}

Berdasarkan rumusan masalah yang dilakukan dalam menetapkan jumlah persedian bahan baku WCP2 dan 7HF agar tidak terjadi keterlambatan pemeriksaan Magnetic Particle Testing (MPI),serta membandingkan perhitungan perusahan dengan Metode EOQ, maka dengan ini diperoleh kesimpulan sebagai berikut:

a. Pemesanan bahan baku WCP-2 menurut kebijakan perusahan adalah adalah rata -rata perbulan pemesanan bahan baku WCP-2 235 cans dengan frekuensi pemesanan sebanyak 12 kali. Sedangkan untuk pemesanan bahan baku WCP-2 untuk mencapai kegiatan inspeksi yang optimal agar tidak terjadi keterlambatan inspeksi menurut metode Economic Order Quantity adalah 1,666 cans dalam pemesanan 2 kali. Biaya Total yang dikeluarkan pada PT. Sucofindo Batam untuk pembelian bahan baku tanpa menggunakan metode Economic Order Quantity adalah sebesar RP. 286.426.536. Sedangkan biaya total mengunakan metode Economic Order Quantity adalah sebesar RP.261.909.260. Perusahan dapat menghemat biaya pemesanan bahan baku hingga sebesar Rp. 24.517.276 maka perusahan dapat menghemat sebesar $8,6 \%$ dalam setahun.

b. Pemesanan bahan baku 7HF menurut kebijakan perusahan adalah adalah rata -rata perbulan pemesanan bahan baku 7HF 117 cans dengan frekuensi pemesanan sebanyak 12 kali. Sedangkan untuk pemesanan bahan baku 7HF untuk mencapai kegiatan inspeksi yang optimal agar tidak terjadi keterlambatan inspeksi menurut metode Economic Order Quantity adalah 1178 cans dalam pemesanan 1 kali. Biaya Total yang dikeluarkan pada PT. Sucofindo Batam untuk pembelian bahan baku tanpa menggunakan metode Economic Order Quantity adalah sebesar RP. 154.384.296. Sedangkan biaya total mengunakan metode Economic Order Quantity adalah sebesar RP.131.171.774. Perusahan dapat menghemat biaya pemesanan bahan baku hingga sebesar Rp. 23.212.522 maka perusahan dapat menghemat sebesar $15 \%$ dalam setahun.

c. Jumlah persedian WCP2 dan 7HF untuk pengaman (Safety stock) yang dibutuhkan oleh perusahan untuk dengan metode Economic Order Quantity adalah Untuk WCP-2 sebanyak 33 cans sedangkan untuk 7HF sebanyak 17 cans.

d. Dengan metode Economic Order Quantity titik pemesanan kembali (reorder point) pada bahan baku WCP-2 dan 7HF, dilakukan pada saat mencapai jumlah 149 cans untuk WCP2 .Sedangkan untuk 7HF dilakukan pada saat mencapai jumlah 74 cans, agar perusahan tidak mengalami kehabisan dan kekurangan bahan baku dan mengindari terjadinya keterlambatan melakukan kegiatan Magnetic Particle Testing (MPI).

SARAN 
Berdasarkan kesimpulan diatas, maka peneliti dapat memberikan saran kepada perusahaan yang dapat digunakan sebagai bahan pertimbangan adalah perusahaan sebaiknya meninjau kembali kebijakan persediaan bahan baku yang selama ini telah dilakukan perusahaan. Perusahaan sebaiknya menerapkan metode EOQ yang telah menghasilkan total biaya persedian yang lebih efisien, menyediakan persediaan pengaman yang jumlahnya sesuai dengan yang dihasilkan jika menggunakan metode EOQ. Untuk mengantisipasi kekurangan bahan baku consumable WCP-2 dan 7HF agar proses inspeksi tidak terganggu, dan menerapkan titik pemesanan kembali atau Reorder Point untuk menghindari keterlambatan pemesanan bahan baku.

\section{UCAPAN TERIMAKASIH}

Dalam penyusunan dan penulisan ini tidak lepas dari bantuan bimbingan serta dukungan dari berbagai pihak. Oleh karena itu dalam kesempatan ini penulis dengan senang hati menyampaikan ucapan beribu terimaksih kepada yang terhormat;

1. Bapak H. Andi Ibrahim, BA selaku Ketua Yayasan Pendidikan Ibnu Sina Batam.

2. Bapak Ir. Larisang. MT.,IPM. selaku Ketua STT Ibnu Sina Batam.

3. Bapak Nanang Alamsyah, ST, MT.,IPM Selaku Ketua Prodi Teknik Industri.

4. Bapak Ir. Larisang. MT.,IPM selaku pembimbing I yang selalu bijaksana memberikan bimbingan, nasehat serta waktunya selama penelitian dan penulisan skripsi ini.

5. Bapak Albertus L.S.,S.T.,M.MT.,IPM selaku pembimbing II yang selalu bijaksana memberikan bimbingan, nasehat serta waktunya selama penelitian dan penulisan skripsi ini.

6. Seluruh Staf dan Mahasiswa Program studi Teknik Industri Ibnu Sina Batam.

7. Seluruh Mahasiswa Teknik Informatika semester 6 dan 7.

8. Orang tua tercinta yang telah sangat banyak memberikan doa dan dukungannya kepada penulis baik secara moril sehingga skripsi ini dapat diselesaikan penulis.

9. Teman-teman semua atas kebersamaan dan bantuan nya yang sangat berarti bagi penulis.

10. Semua pihak yang telah banyak membantu penulis dalam menyelesaikan skripsi ini

\section{DAFTAR PUSTAKA}

Arikunto,S. (2013.133). Prosedur Penelitian: Suatu Pendekatan Praktik. Jakarta: Rineka Cipta

Assauri, Sofjan. (2004:182) Manajemen Pemasaran. Jakarta: Rajawali Press.

Alfabeta. (2013). Metode Penelitian Kuantitatif kualitatif dan R\&D. Bandung, Alfabeta.

Arikunto S, (2006.130) Prosedur Penelitian Suatu Pendekatan Praktik, Ed Revisi VI, Penerbit PT Rineka Cipta, Jakarta.

Asdjudirejda, Lili. (1999.114) Manajemen Produksi. Bandung : Armiko

Assauri, Soyjan. (2008:250) Manajemen Produksi dan Operasi. Jakarta: LPFEUI.

Biegel, John E., (1996), Pengendalian Produksi, Akademika Pressindo, Jakarta.

Carter,William K. (2009.314) Akuntansi Biaya. Edisi 14. Salemba Empat: Jakarta.

Gitosudarmo, Indrio. (2002:101). Manajemen Keuangan .Edisi 4. Yogyakarta: BPFE.

Handoko,T. Hani. (2012). Manajemen Personalia dan Sumber Daya Manusia. Yogyakarta: BPFE 
Harding, H.A., (1996), Manajemen Produksi, Balai Aksara, Jakarta.

Heizer Jay, Render Barry. (2005). Operations Management. Jakarta: Salemba Empat.

Handoko T. Hani, (2000,333) Manajemen Personalia dan Sumberdaya Manusia, Edisi II, Cetakan Keempat Belas, Penerbit BPFE, Yogyakarta.

Harjanto, Eddy., (1997.18) Manajemen Produksi dan Operasi, Gramedia, Jakarta.

Hansen dan Mowen (2005). Management Accounting Buku Edisi 2 ke, Jakarta Salemba, Empat,

Heizer, J. \& Render, B. (2011). Operations Management. Tenth Edition. Pearson, New Jersey, USA.

Indriantoro, nurdan Supomo, bambang (1999).Metodologi Penelitian Bisnis Untuk Akuntansi \& Manajemen. Yogyakarta : Penerbit BPFE.:Erlangga.

Kerlinger. (2006). Asas-asas Penelitian Behavioral Edisi Ketiga. Yogyakarta: Gajah Mada University Press.

Matz, Adolp dkk.(1994). Akuntansi Biaya. Jakarta: Erlangga.

Muhadjir, Noeng, (2000), Metode Penelitian Kualitatif, Jogja: Rake Sarasin.

Bora, M. A., \& Alamsyah, N. (2018). DESIGNING STRATEGY MAPS FOR PRIVATE ENGINEERING COLLEGE.

Nazir ,Mohammad, (2005). Metode Penelitian. Jakarta: Ghalia Indonesia

Veza, Okta. "Simulasi Pengendalian Persedian Gas Menggunakan Metode Monte Carlo dan Pola LCM (Studi Kasus di PT PKM Group Cabang Batam)." Jurnal Teknik Ibnu Sina JTIBSI 1.01 (2016).

R.A. Supriyono, (1999.400). Akuntansi Biaya Buku 1: Pengumpulan Biaya dan Penentuan Harga Pokok, Yogyakarta: BPFE, Edisi 2, Cetakan Ke XII.

Rangkuti, Freddy. (2011). Manajemen Persediaan Aplikasi di Bidang Bisnis. Jakarta.

Setyabudhi, A. L. (2016). Analisa Proses Produksi Ordner dengan Perhitungan Waktu Tunggu. Jurnal Teknik Ibnu Sina JT-IBSI, 1(01).

Schroeder Roger (1995). Pengembilan Keputusan Dalam Suatu Fungsi Operasi. Edisi Ketiga. Erlangga. Jakarta.

Sulastiningsih dan Zulkifli. (1999). Akuntansi Biaya Dilengkapi dengan Isu-isu Kontemporer. Yogyakarta: UPP-AMP YKPN.

Schroeder, Roger.G (1995:4) Pengambilan Keputusa dalam Suatu Fungsi Operasi.

Edisi Ketiga. Jakarta : Erlangga.

Sudana, I. (2011). Manajemen Keuangan Perusahaan Teori dan Praktek. Jakarta

Sugiyono. (2012).Metode Penelitian Bisnis. Bandung : Alfabeta.

https://ejournal.unsrat.ac.id/index.php/emba/article/view/6360 